\title{
Brief interventions for hazardous and harmful alcohol consumption in accident and emergency departments
}

\author{
Marcin Wojnar $^{1,2 *}$ and Andrzej Jakubczyk ${ }^{1}$ \\ ${ }^{1}$ Department of Psychiatry, Medical University of Warsaw, Warsaw, Poland \\ ${ }^{2}$ Department of Psychiatry, University of Michigan, Ann Arbor, MI, USA
}

\section{Edited by:}

Hugo López-Pelayo, Fundació Clínic per la Recerca Biomèdica, Spain

Reviewed by:

Luigi Janiri, Università Cattolica del Sacro Cuore, Italy

Nicolas Bertholet, Lausanne

University Hospital, Switzerland

${ }^{*}$ Correspondence:

Marcin Wojnar, Department of

Psychiatry, Medical University of

Warsaw, Nowowiejska 27, Warsaw

00-665, Poland

e-mail:marcin.wojnar@wum.edu.pl
The prevalence of alcohol abuse among patients treated in accident and emergency departments (A\&E) is considered as substantial. This paper is a narrative review of studies investigating the effectiveness of brief interventions (BI) for hazardous and harmful alcohol consumption in A\&E. A\&E departments in hospitals (and other health care infrastructures) are commonly the place where serious consequences of alcohol drinking are seen and need to be tackled, supporting the suggested theoretical usefulness of delivering $\mathrm{BI}$ in this environment. Available research shows that $\mathrm{BI}$ may be considered a valuable technique for dealing with alcohol-related problems. However, it is suggested that the usefulness of $\mathrm{BI}$ may depend significantly on the target population to be dealt with. BI have proved to be beneficial for male individuals and those patients who do not abuse other psychoactive substances. In contrast, evidence indicates that $\mathrm{BI}$ in $\mathrm{A} \& \mathrm{E}$ settings are not effective at all when dealing with men admitted as a consequence of a violence-related event. In addition, some studies were unable to confirm the effectiveness of $\mathrm{Bl}$ in female population, in emergency setting. Studies investigating the association between drinking patterns and the effectiveness of $\mathrm{Bl}$ also present inconsistent results. Most studies assessing the effectiveness of $\mathrm{BI}$ in $\mathrm{A} \& \mathrm{E}$ settings only adopted a short perspective (looking at the impact up to a maximum of 12 months after the $\mathrm{BI}$ was delivered). When assessing the effects of $\mathrm{Bl}$, both the amount of alcohol consumed and expected reductions in alcohol consequences, such as injuries, can be taken into account. Evidence on the implementation of brief intervention in emergency departments remains inconclusive as to whether there are clear benefits. A variety of outcome measures and assessing procedures were used in the different studies, which have investigated this topic.

Keywords: emergency department, brief intervention, alcohol, implementation, effectiveness

\section{INTRODUCTION}

Accident and emergency departments (A\&E) can be defined as a medical treatment setting specialized in acute care of patients who are admitted presenting rapid symptoms and without prior appointment. The prevalence of alcohol abuse among patients treated (or least diagnosed) in this setting is considered to be substantial. Not surprisingly, alcohol is regarded as one of the leading causes of car accidents (1) as well as injuries in general (2). According to different studies, up to $77 \%(2,3)$ of subjects admitted in A\&E presented an alcohol-related injury, with about $30 \%$ of patients drinking alcohol above recommended levels (4), and between 6 and 22\% $(2,3)$ meeting the criteria of alcohol dependence according to DSM-IV (5). It has been shown that injuries (which are responsible for about $40 \%$ of visits to $A \& E$ ) are especially associated with alcohol drinking. A recent systematic review by Zerhouni et al. (6) has shown that, compared to uninjured patients, individuals with injuries admitted into $\mathrm{A} \& \mathrm{E}$ have a significantly higher probability of presenting elevated blood alcohol levels. Furthermore, in comparison to non-injured individuals entering $\mathrm{A} \& \mathrm{E}$, injured individuals more frequently report having drunk alcohol during the 6-h preceding the fatal event and suffer from drinking-related consequences that adversely affect their social life. Notably, a recent meta-analysis (7) has shown that compared with general population, male subjects with alcoholuse disorders had more than 6.5 -fold higher risk for mortality by injury in 10 years follow-up.

The above mentioned numbers regarding prevalence of alcohol-related problems in A\&E exceed the general frequency of dealing with patients with problem drinking that occurs in other medical settings (8). However, they also show that most of the victims of alcohol-related health problems admitted to A\&E are not alcohol-dependent individuals according to DSM-IV, but rather subjects drinking alcohol in a risky or harmful way. Therefore, actions aimed at reducing the amount of alcohol consumed but not requiring absolute abstinence such as SBIRT (screening, brief intervention, and referral to treatment) programs may be considered particularly useful.

The drinking pattern of special concern in A\&E departments would probably be binge drinking (defined as consuming four or more standard drinks for females and five or more standard drinks for males on one occasion; with one standard drink containing $10 \mathrm{~g}$ of pure ethanol), which has been identified as particularly risky, 
leading to injuries and general health consequences $(9,10)$. Moreover, A\&E is usually the place where individuals are confronted for the first time with serious consequences of their own or others' alcohol drinking. Therefore, the usefulness of brief interventions (BI) in this setting is strongly supported.

The aim of this paper was to summarize the available evidence on the effectiveness of $\mathrm{BI}$ in A\&E departments, as well as the effectiveness of specific BI implementation strategies that have been used in this setting. In order to do so, the Medline database has been searched using the following terms: "brief intervention," "alcohol," "emergency department," "emergency room," "accident and emergency room," "alcohol drinking," "harmful drinking," and "screening." All papers included in this review were published during the last decade, as to provide a summary of the most recent research results. References listed in all selected articles were additionally searched.

\section{EFFICACY OF BI IN ACCIDENT AND EMERGENCY DEPARTMENTS}

A systematic review performed by Nilsen et al. (11) showed that a positive effect of $\mathrm{BI}$ delivered in A\&E on the level of alcohol drinking or the frequency of injuries was observed in 11 out of 12 studies. In addition, more intensive interventions were shown to yield more positive effects. The positive effects were observed in alcohol intake, risky drinking practices, alcohol-related negative consequences, and injury frequency, although in different studies different outcomes were measured and not in all of these outcome measures a positive effect was observed. In more recent randomized controlled trials, the positive effect of BI has been shown to reduce all outcomes: number of drinking days, amount of alcohol drunk on a single occasion, as well as the negative consequences of drinking (12). Notably, the study by Cherpitel et al. provides evidence for effectiveness of BI itself not just as an assessment reactivity (reactivity to the results of questionnaires evaluating amount of alcohol drunk and consequences of drinking), which has been raised as a potential mechanism of BI efficacy (12). In addition, Drummond et al. (13) showed that, contrary to the conclusions of the review by Nilsen et al., more intensive clinical interventions do not add significant benefits to very simple and short interventions. Importantly, BI directed toward subjects in the mild range of drinking severity have been shown to be significantly less effective compared to BI used in individuals within the moderate to heavy range of drinking (12).

In available research studies on $\mathrm{BI}$ in $\mathrm{A} \& \mathrm{E}$ departments, $\mathrm{BI}$ were shown to be effective in the short-term (with a follow-up measure up to 12 months after the BI took place). Most of these studies have assessed effectiveness in 12 months of observation only (1417), whereas the few projects, which followed subjects for a longer period of time, did not confirm long-term effectiveness. On the other hand, in a study by Gwaltney et al. (18) the effects of BI did not emerge immediately after an initial session (evaluation after 1 month), but became visible later - at 3- and 6-months followup visits. In a study by Woolard et al. (19), a reduction of binge drinking days occurred and persisted also during 12 months of observation after delivering BI; however, a significant decrease in the consequences of drinking (such as injuries) was not observed when the BI group was compared to controls. However, results of many studies, also confirmed by meta-analyses $(11,20)$, suggest the opposite association - that BI reduces negative consequences of alcohol rather than the amount of alcohol consumed.

The analysis of the literature shows that the results of the studies on the effectiveness of BI in accident and emergency departments, although in most cases encouraging, remain inconsistent. D'Onofrio et al. (21) described no differences in effectiveness between emergency practitioner-performed Brief Negotiation Interview and usual discharge instructions in terms of either alcohol-use or alcohol-related negative consequences. As previously described, numerous studies showed that the experience of being injured and having to be attended in an emergency department by itself may provide enough motivation for reducing drinking, without any alcohol-related intervention taking place (11). Also, it has been suggested that the environment of A\&E with its chaos, hurry, and quick decisions is not a context offering a desirable atmosphere enabling reflection for change (11). Finally, in the randomized controlled clinical trial performed by Daeppen et al. (22), no effect of BI delivered in A\&E on alcohol drinking outcomes during the follow-up was observed.

Interestingly, the use of SBIRT techniques and questionnaires in a group of non-risky drinkers from emergency settings has been shown to lead to increases in the amount of alcohol drunk (23). The authors suggested as an explanation that these non-risky drinking subjects might have felt to be low consumers and at "safe levels" according to the presented thresholds, which emphasizes the significance of screening in this procedure.

\section{GENDER PERSPECTIVE}

Like in other settings $(24,25)$, results of the studies considering gender differences in the efficacy of BI in accident and emergency departments are inconsistent and conflicting. In a study by Choo et al. (26) BI turned out not to be effective at all in female participants and successful in men, but only for those without a history of involvement in violence. Also in a study by Woodruff et al. (27), men were more likely than women to benefit from BI, However, in another study, no differences between genders were reported (28), whereas, in a study by Blow et al. (16), younger adult women (ages 19-22 years) were most likely to decrease their heavy episodic drinking after receiving brief advice. Despite these contradicting findings, the general trend is for men to be more prone to benefit from BI in A\&E settings. This observation is consistent with research findings showing that alcohol misuse is commonly a primary problem in male individuals, while in women alcohol drinking is often associated with other psychiatric conditions (personality, depressive, or anxiety disorders) (29). Therefore, from this perspective, interventions in women may be more effective when aimed at psychiatric symptoms rather than drinking itself. On the other hand, in male individuals interventions directed on drinking itself may appear to be the most appropriate, reasonable strategy.

\section{BRIEF INTERVENTIONS IN YOUNG INDIVIDUALS}

It has been suggested that emergency departments are especially suitable for interventions of a preventive kind as the age of patients treated in A\&E is lower than in any other medical setting, thus allowing identification of harmful and risky behaviors at early stages. The results of studies conducted in young individuals are 
in accordance with data concerning older patients. Two systematic reviews of literature concerning the effectiveness of $\mathrm{BI}$ in $\mathrm{A} \& \mathrm{E}$ in youngsters and college drinkers show that most of the studies confirm a positive effect of BI in alcohol drinking $(30,31)$. BI turned out to be effective in reducing alcohol intake and risky behaviors associated with drinking [including aggression (32)], although these effects were measured in just a short-term (up to 1 year) perspective $(30,31,33)$. Also, similarly to adult individuals, the female gender was shown to be associated with significantly weaker effects of BI in adolescents (34), and computer-assisted SBIRT procedures were shown to be as effective as those conducted face-to-face (33). However, due to numerous inconsistencies in the results of previous research studies $(33,35)$, clear conclusions concerning the usefulness of delivering BI to the young population in emergency settings cannot be drawn.

\section{PATIENTS' CHARACTERISTICS}

Few studies have investigated the psychological factors contributing to the success (or lack of success) of BI in emergency departments. The small number of studies aimed at more sophisticated elaboration of the procedure is, however, consistent with the core idea of brief intervention, which is that it has to be brief, easy to implement, and not time-consuming. Designing a study assessing psychological factors and investigating detailed mechanisms of BI effectiveness would probably mean that the whole procedure would no longer be brief.

Brief interventions have been shown to be particularly effective in individuals who attribute their injury to alcohol $(36,37)$, suggesting that one of the major aims of BI in accident and emergency departments may be to identify the link between alcohol and injury. As previously mentioned (see Gender Perspective), BI were reported to be ineffective in individuals involved in violent actions (26). The largest reduction in drinking following discharge from A\&E without receiving a BI was observed in subjects characterized by a history of alcohol-related accidents and injuries, and more severe consequences of drinking in general (37). Most likely, this was the group with highest motivation and readiness for change, which has been identified as one of the main factors diminishing the effectiveness of brief intervention (38).

As mentioned previously, a history of involvement in violence (26) and comorbid misuse of other substances (than alcohol) (27) have been shown to decrease the effectiveness of BI in A\&E departments. These observations emphasize the plausible association between the level of psychopathology (e.g., personality disorders) and efficacy of BI in accident and emergency departments. This issue remains a possible objective for further research, although this idea may be challenged by the concept of BI as a short, not complicated, and easy to administer intervention.

\section{IMPLEMENTATION OF BRIEF INTERVENTIONS IN THE EMERGENCY SETTING}

As shown above, the emergency setting seems to be an appropriate place to introduce BI for alcohol drinking, both from a theoretical and a clinical perspective, whereas the efficacy of BI in A\&E has been shown by the results of most of the studies. It has been emphasized that the moment directly after an accident or admission to A\&E may be considered the most "teachable" one.
Moreover, in most of the studies reduction of drinking was even observed in control groups not receiving BI (11), making it reasonable to assume that the injury and admission to A\&E by itself constitute a motivation for change in drinking habits, and thus a favorable moment to take advantage for delivering BI. Notably, the implementation of BI in accident and emergency department has also been recommended in official guidelines for alcohol prevention (39-41). However, the specificity of $\mathrm{A} \& \mathrm{E}$ departments includes brevity of contact with patients, overloading of the staff, and engaging in numerous activities that may be considered more important and more directly associated with life-saving approaches that remain the core of $A \& E$ functioning. In addition, a lack of adequate training has been suggested as a significant barrier in implementing BI in the emergency setting $(42,43)$.

This clear discrepancy between the needs and capabilities has been confirmed in numerous studies showing that less than onethird of accident and emergency departments offers BI for alcohol drinking by trained personnel (42). Such surprisingly low prevalence of BI implementation stimulated studies aimed at identifying barriers and facilitators of SBIRT use in the emergency setting. Among possible facilitators, presence of official guidelines and health policy (44), as well as use of computer-assisted screening and brief intervention procedures $(45,46)$ were emphasized. In addition, during the introduction of a screening procedure into everyday routine practice (47), a positive change in attitudes toward screening and BI of A\&E staff was observed, as they reported to experience that the procedure worked well and that patients were willing to cooperate.

\section{DIFFERENT WAYS OF IMPLEMENTING BRIEF INTERVENTION}

Taking into account the barriers and facilitators identified in previous research for implementing BI in emergency settings, a few recent research studies focused on the possibility of using a computer-assisted SBIRT procedure in A\&E. The results of these studies show that the use of such technological supports substantially increases screening rates (even up to $89-97 \%)(45,46)$, but the outcomes in terms of effectiveness remain inconsistent (11). Therefore, more research is needed to establish knowledge about possible benefits of technologically modified SBIRT procedures.

Other research analyzing the kinds of intervention performed, showed that individuals for whom alcohol was not a factor involved in the injury or cause of admission, although they presented symptoms of risky or harmful alcohol use justifying the delivery of BI benefited from a counselor-guided intervention (consideration of the risks related to their alcohol use), whereas subjects already experiencing previous consequences of alcohol use did not show added benefit from the counselor intervention compared to receiving the feedback report only (28).

Telephone-applied BI delivered orally decreased impaired driving and alcohol-related injuries in patients discharged from $\mathrm{A} \& \mathrm{E}$ with greatest effects for those with more severe alcohol drinking $(48,49)$. However, this type of intervention was not shown to be effective in terms of change in alcohol consumption and other alcohol-related consequences (49). In a recent multisite randomized clinical trial, brief intervention using personalized feedback delivered before the subject was discharged from A\&E and followed by a telephone booster once discharged, was shown 
to be the most effective way of reducing alcohol drinking in $\mathrm{A} \& \mathrm{E}$ patients (50).

\section{CONCLUSION}

Available research studies show that BI may be considered a useful technique for dealing with alcohol problems in A\&E departments. However, it is suggested that the usefulness of BI may depend significantly on the population that it is offered to. The effects of BI can be measured both in terms of the amount of alcohol consumed and in terms of expected reductions in alcohol consequences, such as injuries, and therefore, different outcome measures were taken into consideration and a variety of assessing procedures were used in the studies addressing this topic. In addition, different methods of BI implementation were assessed, hampering the comparison between results. It is also important to consider that the number of research studies on the effectiveness of BI in A\&E settings is still relatively small, while the most important methodological limitation of such studies consists in the fact that in most of them BI effectiveness was assessed in a short (up to 12 months) perspective. Although, it may seem challenging for a briefintervention to result in significant long-term effects, it would be useful to examine their effectiveness in longitudinal research studies designed for longterm observation, also providing more insight as to whether BI delivered in $A \& E$ departments have a significantly greater impact in reducing drinking and alcohol-related harm than the effect of being admitted into A\&E after an alcohol-related event in itself.

\section{REFERENCES}

1. Martin TL, Solbeck PA, Mayers DJ, Langille RM, Buczek Y, Pelletier MR. A review of alcohol-impaired driving: the role of blood alcohol concentration and complexity of the driving task. J Forensic Sci (2013) 58:1238-50. doi:10.1111/1556-4029.12227

2. Cherpitel CJ. Alcohol and injuries: a review of international emergency room studies since 1995. Drug Alcohol Rev (2007) 26:201-14. doi:10.1080/ 09595230601146686

3. Browne AL, Newton M, Gope M, Schug SA, Wood F, Allsop S. Screening for harmful alcohol use in Australian trauma settings. Injury (2013) 44:110-7. doi:10.1016/j.injury.2012.01.008

4. Hankin A, Daugherty M, Bethea A, Haley L. The Emergency Department as a prevention site: a demographic analysis of substance use among ED patients. Drug Alcohol Depend (2013) 130:230-3. doi:10.1016/j.drugalcdep.2012.10.027

5. APA. Diagnostic and Statistical Manual of Mental Disorders, 4th ed, Text Revision. Washington, DC: American Psychiatric Association (2000).

6. Zerhouni O, Bègue L, Brousse G, Carpentier F, Dematteis M, Pennel L, et al. Alcohol and violence in the emergency room: a review and perspectives from psychological and social sciences. Int J Environ Res Public Health (2013) 10:4584-606. doi:10.3390/ijerph10104584

7. Roerecke M, Rehm J. Cause-specific mortality risk in alcohol use disorder treatment patients: a systematic review and meta-analysis. Int J Epidemiol (2014) 3:906-19. doi:10.1093/ije/dyu018

8. Madras BK, Compton WM, Avula D, Stegbauer T, Stein JB, Clark HW. Screening, brief interventions, referral to treatment (SBIRT) for illicit drug and alcohol use at multiple healthcare sites: comparison at intake and 6 months later. Drug Alcohol Depend (2009) 99:280-95. doi:10.1016/j.drugalcdep.2008.08.003

9. Nordqvist C, Holmqvist M, Nilsen P, Bendtsen P, Lindqvist K. Usual drinking patterns and non-fatal injury among patients seeking emergency care. Public Health (2006) 120:1064-73. doi:10.1016/j.puhe.2006.06.007

10. Gastfriend DR, Garbutt JC, Pettinati HM, Forman RF. Reduction in heavy drinking as a treatment outcome in alcohol dependence. J Subst Abuse Treat (2007) 33:71-80. doi:10.1016/j.jsat.2006.09.008

11. Nilsen P, Baird J, Mello MJ, Nirenberg T, Woolard R, Bendtsen P, et al. A systematic review of emergency care brief alcohol interventions for injury patients. J Subst Abuse Treat (2008) 35:184-201. doi:10.1016/j.jsat.2007.09.008
12. Cherpitel CJ, Korcha RA, Moskalewicz J, Swiatkiewicz G, Ye Y, Bond J. Screening, brief intervention, and referral to treatment (SBIRT): 12-month outcomes of a randomized controlled clinical trial in a Polish emergency department. Alcohol Clin Exp Res (2010) 11:1922-8. doi:10.1111/j.1530-0277.2010. 01281.x

13. Drummond C, Deluca P, Coulton S, Bland M, Cassidy P, Crawford M, et al. The effectiveness of alcohol screening and brief intervention in emergency departments: a multicentre pragmatic cluster randomized controlled trial. PLoS One (2014) 9(6):e99463. doi:10.1371/journal.pone.0099463

14. Mello MJ, Longabaugh R. A brief intervention by emergency department providers decreased 12 month alcohol use. Evid Based Med (2013) 18:e24. doi:10.1136/eb-2012-101024

15. Academic ED SBIRT Research Collaborative. The impact of screening, brief intervention and referral for treatment in emergency department patients' alcohol use: a 3-, 6- and 12-month follow-up. Alcohol Alcohol (2010) 45:514-9. doi:10.1093/alcalc/agq058

16. Blow FC, Barry KL, Walton MA, Maio RF, Chermack ST, Bingham CR, et al. The efficacy of two brief intervention strategies among injured, at-risk drinkers in the emergency department: impact of tailored messaging and brief advice. J Stud Alcohol (2006) 67:568-78.

17. Korcha RA, Cherpitel CJ, Moskalewicz J, Swiatkiewicz G, Bond J, Ye Y. Readiness to change, drinking, and negative consequences among Polish SBIRT patients. Addict Behav (2012) 37:287-92. doi:10.1016/j.addbeh.2011.11.006

18. Gwaltney CJ, Magill M, Barnett NP, Apodaca TR, Colby SM, Monti PM. Using daily drinking data to characterize the effects of a brief alcohol intervention in an emergency room. Addict Behav (2011) 36:248-50. doi:10.1016/j.addbeh. 2010.10.010

19. Woolard R, Baird J, Longabaugh R, Nirenberg T, Lee CS, Mello MJ, et al. Project reduce: reducing alcohol and marijuana misuse: effects of a brief intervention in the emergency department. Addict Behav (2013) 38:1732-9. doi:10.1016/j.addbeh.2012.09.006

20. Havard A, Shakeshaft A, Sanson-Fisher R. Systematic review and meta-analyses of strategies targeting alcohol problems in emergency departments: interventions reduce alcohol-related injuries. Addiction (2008) 103:368-76. doi:10.1111/ j.1360-0443.2007.02072.x discussion 77-8,

21. D'Onofrio G, Pantalon MV, Degutis LC, Fiellin DA, Busch SH, Chawarski $\mathrm{MC}$, et al. Brief intervention for hazardous and harmful drinkers in the emergency department. Ann Emerg Med (2008) 51:742.e-50.e. doi:10.1016/j. annemergmed.2007.11.028

22. Daeppen JB, Gaume J, Bady P, Yersin B, Calmes JM, Givel JC, et al. Brief alcohol intervention and alcohol assessment do not influence alcohol use in injured patients treated in the emergency department: a randomized controlled clinical trial. Addiction (2007) 8:1224-33. doi:10.1111/j.1360-0443.2007.01869.x

23. Nordqvist C, Wilhelm E, Lindqvist K, Bendtsen P. Can screening and simple written advice reduce excessive alcohol consumption among emergency care patients? Alcohol Alcohol (2005) 40:401-8. doi:10.1093/alcalc/agh175

24. Kaner EFS, Dickinson HO, Beyer FR, Campbell F, Schlesinger C, Heather $\mathrm{N}$, et al. Effectiveness of brief alcohol interventions in primary care populations. Cochrane Database Syst Rev (2007):CD004148. doi:10.1002/14651858. CD004148.pub3

25. Reinhardt S, Bischof G, Grothues J, John U, Meyer C, Rumpf HJ. Gender differences in the efficacy of brief interventions with a stepped care approach in general practice patients with alcohol-related disorders. Alcohol Alcohol (2008) 43:334-40. doi:10.1093/alcalc/agn004

26. Choo EK, McGregor AJ, Mello MJ, Baird J. Gender, violence and brief interventions for alcohol in the emergency department. Drug Alcohol Depend (2013) 127:115-21. doi:10.1016/j.drugalcdep.2012.06.021

27. Woodruff SI, Eisenberg K, McCabe CT, Clapp JD, Hohman M. Evaluation of California's alcohol and drug screening and brief intervention project for emergency department patients. West J Emerg Med (2013) 14:263-70. doi:10.5811/westjem.2012.9.11551

28. Barnett NP, Apodaca TR, Magill M, Colby SM, Gwaltney C, Rohsenow DJ, et al. Moderators and mediators of two brief interventions for alcohol in the emergency department. Addiction (2010) 105:452-65. doi:10.1111/j.1360-0443.2009. 02814.x

29. Nolen-Hoeksema S, Hilt L. Possible contributors to the gender differences in alcohol use and problems. J Gen Psychol (2006) 133:357-74. doi:10.3200/GENP. 133.4.357-374 
30. Taggart IH, Ranney ML, Howland J, Mello MJ. A systematic review of emergency department interventions for college drinkers. J Emerg Med (2013) 45:962-8. doi:10.1016/j.jemermed.2013.05.065

31. Newton AS, Dong K, Mabood N, Ata N, Ali S, Gokiert R, et al. Brief emergency department interventions for youth who use alcohol and other drugs: a systematic review. Pediatr Emerg Care (2013) 29:673-84. doi:10.1097/PEC. 0b013e31828ed325

32. Walton MA, Chermack ST, Shope JT, Bingham CR, Zimmerman MA, Blow FC, et al. Effects of a brief intervention for reducing violence and alcohol misuse among adolescents: a randomized controlled trial. JAMA (2010) 5:527-35. doi:10.1001/jama.2010.1066

33. Sommers MS, Lyons MS, Fargo JD, Sommers BD, McDonald CC, Shope JT, et al. Emergency department-based brief intervention to reduce risky driving and hazardous/harmful drinking in young adults: a randomized controlled trial. Alcohol Clin Exp Res (2013) 37:1753-62. doi:10.1111/acer.12142

34. Becker SJ, Spirito A, Hernandez L, Barnett NP, Eaton CA, Lewander W, et al. Trajectories of adolescent alcohol use after brief treatment in an Emergency Department. Drug Alcohol Depend (2012) 125:103-9. doi:10.1016/j.drugalcdep. 2012.03.021

35. Patton R, Deluca P, Kaner E, Newbury-Birch D, Phillips T, Drummond C. Alcohol screening and brief intervention for adolescents: the how, what and where of reducing alcohol consumption and related harm among young people. Alcohol Alcohol (2014) 49:207-12. doi:10.1093/alcalc/agt165

36. Walton MA, Goldstein AL, Chermack ST, McCammon RJ, Cunningham RM, Barry KL, et al. Brief alcohol intervention in the emergency department: moderators of effectiveness. J Stud Alcohol Drugs (2008) 69:550-60.

37. Cochran G, Field C, Caetano R. Injury-related consequences of alcohol misuse among injured patients who received screening and brief intervention for alcohol: a latent class analysis. Subst Abus (2014) 35:153-62. doi:10.1080/08897077. 2013.820679

38. Stein LA, Minugh PA, Longabaugh R, Wirtz P, Baird J, Nirenberg TD, et al. Readiness to change as a mediator of the effect of a brief motivational intervention on posttreatment alcohol-related consequences of injured emergency department hazardous drinkers. Psychol Addict Behav (2009) 23:185-95. doi: $10.1037 / \mathrm{a} 0015648$

39. National Institute for Health and Clinical Excellence (NICE). Alcohol-Use Disorders: Diagnosis, Assessment and Management of Harmful Drinking and Alcohol Dependence. (0000). Available at: http://www.nice.org.uk/guidance/CG115

40. D’Onofrio G, Bernstein E, Bernstein J, Woolard RH, Brewer PA, Craig SA, et al. Patients with alcohol problems in the emergency department, part 1: improving detection. SAEM Substance Abuse Task Force. Society for Academic Emergency Medicine. Acad Emerg Med (1998) 5:1200-9. doi:10.1111/j.1553-2712. 1998.tb02696.x

41. D’Onofrio G, Bernstein E, Bernstein J, Woolard RH, Brewer PA, Craig SA, et al. Patients with alcohol problems in the emergency department, part 2: intervention and referral. SAEM Substance Abuse Task Force. Society for Academic Emergency Medicine. Acad Emerg Med (1998) 5:1210-7. doi:10.1111/j.15532712.1998.tb02697.x

42. Cunningham RM, Harrison SR, McKay MP, Mello MJ, Sochor M, Shandro JR, et al. National survey of emergency department alcohol screening and intervention practices. Ann Emerg Med (2010) 55:556-62. doi:10.1016/j. annemergmed.2010.03.004

43. Schermer CR, Gentilello LM, Hoyt DB, Moore EE, Moore JB, Rozycki GS, et al. National survey of trauma surgeons' use of alcohol screening and brief intervention. J Trauma (2003) 55:849-56. doi:10.1097/01.TA.0000091110. 83692.38

44. Patton R, O'Hara P. Alcohol: signs of improvement. The 2nd national Emergency Department survey of alcohol identification and intervention activity. Emerg Med J (2013) 30:492-5. doi:10.1136/emermed-2012-201527

45. Johnson JA, Woychek A, Vaughan D, Seale JP. Screening for at-risk alcohol use and drug use in an emergency department: integration of screening questions into electronic triage forms achieves high screening rates. Ann Emerg Med (2013) 62:262-6. doi:10.1016/j.annemergmed.2013.04.011

46. Murphy MK, Bijur PE, Rosenbloom D, Bernstein SL, Gallagher EJ. Feasibility of a computer-assisted alcohol SBIRT program in an urban emergency department: patient and research staff perspectives. Addict Sci Clin Pract (2013) 8:2. doi:10.1186/1940-0640-8-2

47. Nordqvist C, Johansson K, Lindqvist K, Bendtsen P. Attitude changes among emergency department triage staff after conducting routine alcohol screening. Addict Behav (2006) 31:191-202. doi:10.1016/j.addbeh.2005.04.021

48. Mello MJ, Longabaugh R, Baird J, Nirenberg T, Woolard R. DIAL: a telephone brief intervention for high-risk alcohol use with injured emergency department patients. Ann Emerg Med (2008) 51:755-64. doi:10.1016/j.annemergmed.2007. 11.034

49. Mello MJ, Baird J, Nirenberg TD, Lee C, Woolard R, Longabaugh R. DIAL: a randomised trial of a telephone brief intervention for alcohol. Inj Prev (2013) 19:44-8. doi:10.1136/injuryprev-2012-040334

50. Field C, Walters S, Marti CN, Jun J, Foreman M, Brown C. A multisite randomized controlled trial of brief intervention to reduce drinking in the trauma care setting: how brief is brief? Ann Surg (2014) 5:873-80. doi:10.1097/SLA. 0000000000000339

Conflict of Interest Statement: The authors declare that the research was conducted in the absence of any commercial or financial relationships that could be construed as a potential conflict of interest.

Received: 01 August 2014; accepted: 17 October 2014; published online: 03 November 2014.

Citation: Wojnar $M$ and Jakubczyk A (2014) Brief interventions for hazardous and harmful alcohol consumption in accident and emergency departments. Front. Psychiatry 5:152. doi: 10.3389/fpsyt.2014.00152

This article was submitted to Addictive Disorders and Behavioral Dyscontrol, a section of the journal Frontiers in Psychiatry.

Copyright (C) 2014 Wojnar and Jakubczyk. This is an open-access article distributed under the terms of the Creative Commons Attribution License (CC BY). The use, distribution or reproduction in other forums is permitted, provided the original author(s) or licensor are credited and that the original publication in this journal is cited, in accordance with accepted academic practice. No use, distribution or reproduction is permitted which does not comply with these terms. 